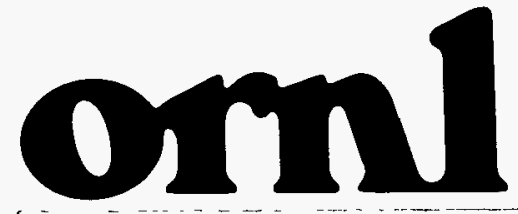

OAK RIDGE NATIONAL LABORATORY

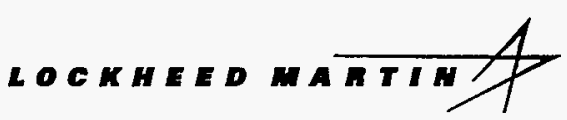

\section{COMPRESSIVE CREEP RESPONSE OF T1000G/RS-14 GRAPHITE/POLYCYANATE COMPOSITE MATERIALS}

J. M. Starbuck

Oak Ridge National Laboratory

Date Published - January, 1998
MANAGED AND OPERATED BY

LOCKHEED MARTN ENERGY RESEARCH CORPORATION FOR THE UNTED STATES DEPARTMENT OF ENERGY
Engineering Technology Division

$$
\begin{gathered}
\text { RECEIVED } \\
\text { MAY O } 81998 \\
\text { OSTI }
\end{gathered}
$$

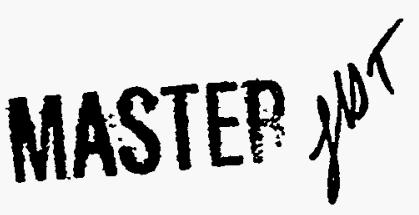

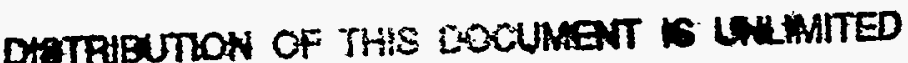




\section{DISCLAIMER}

This report was prepared as an account of work sponsored by an agency of the United States Government. Neither the United States Government nor any agency thereof, nor any of their employees, makes any warranty, express or implied, or assumes any legal liability or responsibility for the accuracy, completeness, or usefulness of any information, apparatus, product, or process disclosed, or represents that its use would not infringe privately owned rights. Reference herein to any specific commercial product, process, or service by trade name, trademark, manufacturer, or otherwise, does not necessarily constitute or imply its endorsement, recommendation, or favoring by the United States Government or any agency thereof. The views and opinions of authors expressed herein do not necessarily state or reflect those of the United States Government or any agency thereof. 


\section{DISCLAIMER}

Portions of this document may be illegible electronic image products. Images are produced from the best available original document. 
ORNL-6937

Engineering Technology Division

\title{
COMPRESSIVE CREEP RESPONSE OF T1000G/RS-14 GRAPHITE/POLYCYANATE COMPOSITE MATERIALS
}

\author{
J. M. Starbuck \\ Oak Ridge National Laboratory
}

Date Published - January, 1998

Prepared by the

Oak Ridge National Laboratory

Oak Ridge, Tennessee 37831-8048 managed by

LOCKHEED MARTIN ENERGY RESEARCH CORPORATION for the

U.S. DEPARTMENT OF ENERGY under contract DE-AC05-96OR22464 


\section{TABLE OF CONTENTS}

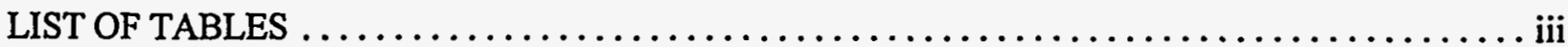

LIST OF FIGURES $\ldots \ldots \ldots \ldots \ldots \ldots \ldots \ldots \ldots \ldots \ldots \ldots \ldots \ldots \ldots \ldots \ldots \ldots \ldots \ldots \ldots \ldots$

LIST OF ACRONYMS $\ldots \ldots \ldots \ldots \ldots \ldots \ldots \ldots \ldots \ldots \ldots \ldots \ldots \ldots \ldots \ldots \ldots \ldots$

ABSTRACT $\ldots \ldots \ldots \ldots \ldots \ldots \ldots \ldots \ldots \ldots \ldots \ldots \ldots \ldots \ldots \ldots \ldots \ldots \ldots \ldots \ldots \ldots$

INTRODUCTION $\ldots \ldots \ldots \ldots \ldots \ldots \ldots \ldots \ldots \ldots \ldots \ldots \ldots \ldots \ldots \ldots \ldots \ldots \ldots \ldots \ldots \ldots \ldots \ldots$

1. RS-14 RESIN COMPRESSIVE RESPONSE $\ldots \ldots \ldots \ldots \ldots \ldots \ldots \ldots \ldots \ldots \ldots \ldots \ldots \ldots$

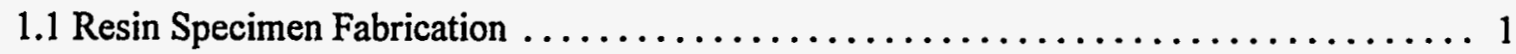

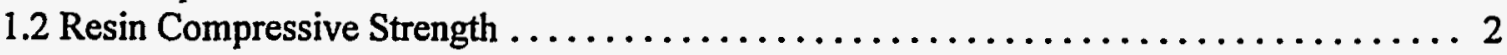

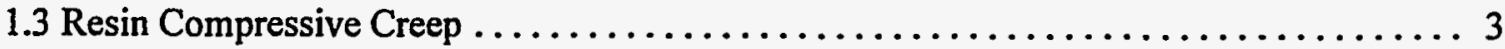

2. T1000G/RS-14 COMPOSITE TRANSVERSE COMPRESSIVE RESPONSE $\ldots \ldots \ldots \ldots \ldots \ldots 14$

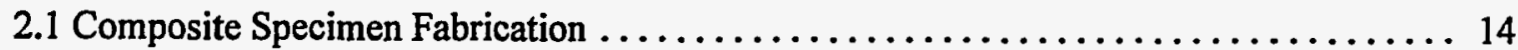

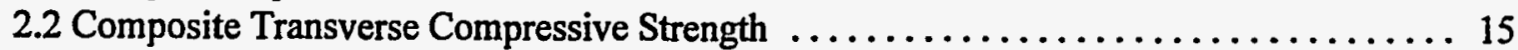

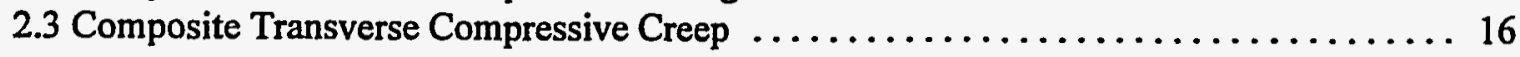

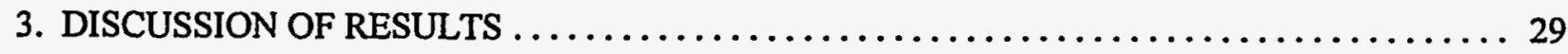

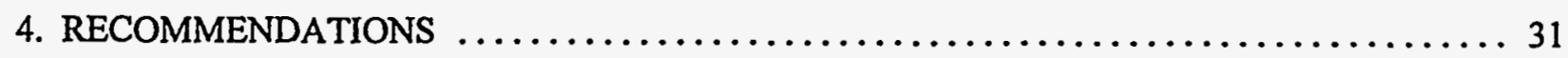

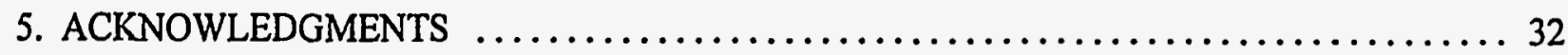

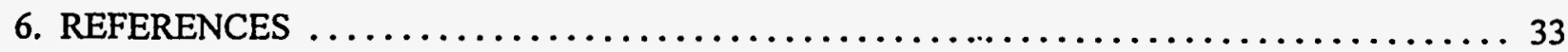




\section{LIST OF TABLES}

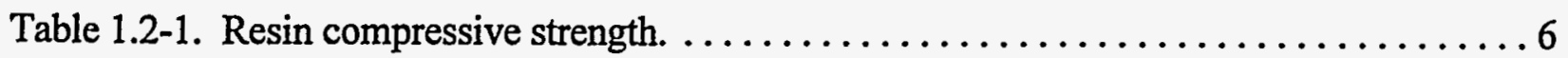

Table 1.3-1. Resin compressive creep test matrix. $\ldots \ldots \ldots \ldots \ldots \ldots \ldots \ldots \ldots$

Table 1.3-2. Results for RS-14 resin compressive creep tests. ................ 10

Table 2.2-1. Results from composite transverse compressive strength tests. .......... 19

Table 2.3-1. Test matrix for composite transverse compressive creep tests. $\ldots \ldots \ldots \ldots 21$

Table 2.3-2. Results for the T1000G/RS-14 composite transverse compressive creep tests $\ldots 22$ 


\section{LIST OF FIGURES}

Fig. 1.2-1. Stress-strain responses for RS-14 resin tested at ambient temperatures. . . . . . 7

Fig. 1.2-2. Stress-strain response for RS-14 resin tested at $275^{\circ} \mathrm{F} \ldots \ldots \ldots \ldots \ldots \ldots \ldots . \ldots$

Fig. 1.3-1. Effect of process and test environments on RS-14 resin compressive creep. . . . . 11

Fig. 1.3-2. Effect of post-cure temperature on RS-14 resin compressive creep. $\ldots \ldots \ldots \ldots 12$

Fig. 1.3-3. Effect of test temperature on RS-14 resin compressive creep. $\ldots \ldots \ldots \ldots \ldots 13$

Fig. 2.1-1. Composite transverse compression test specimen geometries. $\ldots \ldots \ldots \ldots \ldots 18$

Fig. 2.2-1. Typical stress-strain curves for composite transverse compression. . . . . . . 20

Fig. 2.3-1. Total strains for composite transverse compressive creep tests. ...........23

Fig. 2.3-2. Effect of test temperature on composite transverse compressive creep. . . . . . 24

Fig. 2.3-3. Effect of applied stress level on composite transverse compressive creep. $\ldots \ldots 25$

Fig. 2.3-4. Magnitude of creep strains for composite transverse compressive creep. $\ldots \ldots \ldots 26$

Fig. 2.3-5. Nonlinear least-squares regression fit for power law parameters. $\ldots \ldots \ldots \ldots 27$

Fig. 2.3-6. Ten-year prediction based on power law model. $\ldots \ldots \ldots \ldots \ldots \ldots \ldots \ldots 28$ 


\section{LIST OF ACRONYMS}

ASTM American Society of Testing and Materials

CV Coefficient of Variation

ID Inner Diameter

psi pounds per Square Inch

ksi $\quad 10^{3}$ pounds per Square Inch

Msi $\quad 10^{6}$ pounds per Square Inch

OD Outer Diameter 


\begin{abstract}
The response of a T1000G/RS-14 graphite/polycyanate composite material system to transverse compressive loads is quantified via experimentation. The primary objective of the work was to quantify the effects of process environment and test environment on the T1000G/RS-14 compressive creep response. Tests were conducted on both the neat resin and the composite material system. In addition to the creep tests, static compressive strength tests were conducted to define the stress-strain response.

The creep behavior for the RS-14 resin was quantified by conducting a series of tests to study the effects of different process environments (air and nitrogen), different cure temperatures, and different test environments (air and vacuum). The combined effect on the RS-14 resin compressive creep of processing in nitrogen and testing under vacuum versus processing in air and testing in air was a $47 \%$ decrease in the creep strain after $2177 \mathrm{hr}$. The test environment appeared to have a greater effect on the resin creep than the process environment.
\end{abstract}

Following the conclusion of the resin creep tests, composite transverse compressive creep tests were conducted. The composite creep test cylinder was post-cured in a nitrogen environment prior to machining test specimens and all tests were conducted in a vacuum environment. The series of tests investigated the effects of initial stress level and test temperature on the creep behavior. At the end of the $2000-\mathrm{hr}$ tests at $275^{\circ} \mathrm{F}$ on specimens stressed at $10,000 \mathrm{psi}$, the nitrogen-processed and vacuum-tested conditions reduced the composite transverse compressive creep strain by $19 \%$ compared to processing in air and testing in air. The effects of process and test environment on the creep behavior are not as great for the composite system as they were for the neat resin, primarily because of the low resin content in the composite material system.

At the $275^{\circ} \mathrm{F}$ test temperature there was a significant increase in the composite transverse compressive creep strain between the 6000-psi and 10,000-psi stress levels. Despite the reduction in creep strains due to processing in a nitrogen environment, dimensional stability of the T1000G/RS-14 composite at high transverse compressive stress levels and high temperatures may still be an issue when selecting this system for future applications. 


\section{INTRODUCTION}

The overall objective of this effort was to evaluate and characterize an advanced composite material system that could be used in higher temperature applications that exceed the capability of current epoxy resin systems. Two examples are future aerospace and energy storage applications. The primary structural component under consideration is a composite ring subjected to rotational body forces, where the fiber-direction strength is a more critical design parameter than stiffness. Also, the dimensional stability of the composite material system is a critical parameter. The results from these tests and corresponding data analyses were aimed at reducing the risk of selecting a composite material for possible use in future designs.

The quality of composite structural components required for this type of application is best achieved by using the wet filament winding process. The advantages of wet-filament-winding are that it permits instantaneous and in-situ ply-by-ply consolidation during the lay-up of the composite. Resin bleed-out is almost immediate with the application of each layer. These process characteristics lead to reduced fiber wrinkling and voids in thick constructions, particularly when compared to composites made via the pre-preg lay-up fabrication method in which resin bleed-out and ply consolidation occur after the total thickness has been laid up. Another advantage of wet-filamentwinding is the capability to achieve very high fiber volume fractions which translates into high fiberdirection composite tensile strengths. The disadvantages of the wet-filament-winding process are typically low transverse shear strengths and a heavy dependence on the selected resin.

The material system that was selected for this investigation was an ultra-high-strength carbon fiber with a polycyanate resin. The highest strength carbon fiber currently on the market is produced by Toray Industries and is designated by T1000G. The reported strength for this fiber ranges from 900-950 ksi. The cyanate ester class of thermoset matrix resins, also called polycyanates, have inherent qualities that make them an excellent choice for a material system that will be exposed to a space or vacuum environment. In general, polycyanate resins have low moisture absorption, good fiber wet-out properties, low out-gassing, good radiation stability, good resistance to microcracking, and superior heat resistance. Also, the polycyanate resins are amenable to the wet-filament-winding 
process with only slight modifications to existing processes for epoxy resins. The selected polycyanate resin was RS-14 produced by YLA, Inc.

The details of the fabrication and wet-filament winding process for the T1000G/RS-14 system were described by Frame and Starbuck ${ }^{1}$, and Frame ${ }^{2}$. Also, the experimental results for the static strengths and fiber-direction performance were discussed by Frame ${ }^{2}$ and Starbuck ${ }^{3}$. A preliminary investigation of the dimensional stability of T1000G/RS-14, based on the results from transverse compressive creep tests, was conducted by Starbuck ${ }^{3}$. This work was expanded to study the effects of processing and testing environments on the transverse compressive creep response and the results are documented in this report. 


\section{RS-14 RESIN COMPRESSIVE RESPONSE}

The primary objective of this study was to quantify the effects of process environment and test environment on the T1000G/RS-14 compressive creep response. Tests were conducted on both the neat resin and the composite material system. In addition to the creep tests, static compressive strength tests were conducted to define the stress-strain response. The results from the neat resin tests are discussed in this section.

The compressive strength and creep behavior for the RS-14 resin was quantified by conducting a series of tests to study the effects of different process environments, different cure temperatures, and different test environments. The different process environments were air and nitrogen. The different test environments were air and vacuum. The initial creep test matrix was redefined as a result of difficulty in the manufacturing of the test specimens. This led to investigating the effect of post-cure temperature by testing specimens that had been cured at $470^{\circ} \mathrm{F}$, $520^{\circ} \mathrm{F}$, and a third temperature that was in between these two temperatures.

\subsection{Resin Specimen Fabrication}

The test specimen geometry was a cast rod having a nominal 0.5 in. diameter and a length of 1.5 in. The slenderness ratio for the specimen, i.e., the ratio of the length to least radius of gyration, was equal to 12:1. For a uniform circular cross-section, the radius of gyration is 0.250 times the diameter. This was a preferred specimen size according to ASTM D695M-85, Standard Test Method for Compressive Properties of Rigid Plastics, which recommends a slenderness ratio in the range of $11: 1$ to $16: 1$.

The specimens were cast in a glass test tube treated with a mold release agent to facilitate removal after curing. Any entrapped air caused by pouring the resin into the test tube was removed by centrifuging. The specimens were pre-cured at $280^{\circ} \mathrm{F}$ at a ramp rate of $2^{\circ} \mathrm{F} / \mathrm{min}$ and a hold time of $3 \mathrm{hr}$. The specimens were returned to ambient temperature, removed from the test tubes, and then post-cured. The ramp rate for the post-cure was $3^{\circ} \mathrm{F} / \mathrm{min}$ with a hold time of $4 \mathrm{hr}$. For specimens cured in the nitrogen environment, there was a 3- to 4-hr purge time prior to initiating any cure cycle. 
After the specimens were post-cured, they were machined to length with the end faces being flat and parallel.

The planned manufacturing process was to utilize an autoclave system without the pressure cycle for curing the specimens. The autoclave was a convenient method for controlling both the temperature and environment. The first batch of specimens were cured in the air environment at a post-cure temperature of $520^{\circ} \mathrm{F}$. The second batch of specimens was to be identical to the first but with a nitrogen environment. However, during the post-cure cycle the autoclave heaters malfunctioned and the specimens were only cured at $470^{\circ} \mathrm{F}$. It was determined that the autoclave heaters needed to be replaced and an alternative curing process was required to maintain schedule. Consequently, a vacuum furnace was used as a replacement for the autoclave. The cavity in the furnace was such that the specimens had to be separated into two batches. The two batches were then positioned at two different vertical locations in the furnace. After curing the specimens and removing them from the furnace it was observed that the two batches had different colors. It was postulated that this was caused by a thermal gradient in the furnace. The top batch, which was darker in color, was determined to have been cured at $520^{\circ} \mathrm{F}$ since this was where the control thermocouple was located. The bottom batch, which was lighter in color, was assumed to have been cured at a temperature less than $520^{\circ} \mathrm{F}$ but this was never verified via a separate temperature measurement.

\subsection{Resin Compressive Strength}

Static compressive strength tests were conducted on specimens taken from each of the four groups of processing conditions. The specimens were strain gaged for determining the stress-strain response and modulus. The modulus was calculated using the initial linear portion of the stressstrain curve between $0.2-0.7 \%$ strain. Also, the yield stress and yield strain, calculated using the $0.2 \%$ offset method, were determined from the stress-strain curve. The results are shown in Table 1.2-1 for the ambient test temperature and for the elevated test temperature of $275^{\circ} \mathrm{F}$. The stressstrain responses are provided in Fig. 1.2-1 and Fig. 1.2-2 for the ambient and $275^{\circ} \mathrm{F}$ test temperatures, respectively. 
The results in Table 1.2-1 indicate there was a minimal affect of process environment on the ultimate compressive strength, yield strength, yield strain, and modulus of the RS-14 resin. The post-cure temperature had a greater effect in that the specimens cured at a lower temperature had slightly lower values for all these quantities. However, this effect was still less than $5 \%$. This was not unexpected because the compressive strength of an unreinforced resin is not as sensitive to flaws as the tensile strength. Also, the compression test specimen geometry has a smaller surface to volume ratio than the tensile specimen geometry thereby making it less sensitive to the effects of carbamate formation and surface oxidation. The effects of test temperature were significant with a $38 \%$ reduction in strength and a $21 \%$ reduction in modulus for testing at $275^{\circ} \mathrm{F}$ compared to ambient.

\subsection{Resin Compressive Creep}

The resin compressive creep tests were conducted in accordance with Table 1.3-1. All of the creep tests were conducted using $3000 \mathrm{psi}$ as the initial applied stress level and $275^{\circ} \mathrm{F}$ as the test temperature. One additional test was conducted at $325^{\circ} \mathrm{F}$ to study the effect of test temperature on the measured creep response. The specimens were dead-weight loaded using 20:1 mechanical advantage lever-arm creep stands and special fixtures for applying the compressive loads. Each specimen was placed in an environmental chamber, pumped down to obtain the vacuum, heated to the prescribed test temperature, then pre-conditioned for $24 \mathrm{hr}$. Afterwards, a motorized weight pan was used to smoothly apply the load at a constant rate. As shown in Figs. 1.2-1 and 1.2-2, the 3000psi applied stress level was within the initial linear portion of the stress-strain curve. A dummy specimen was placed in each environmental chamber to provide active thermal compensation for the strain gages. Thermocouples were used in each chamber to monitor the specimen temperature as well as the surrounding air temperature. A computerized data acquisition system was used to automatically collect the strain gage and thermocouple data. A sampling rate of once per second was used during loading and the first $2 \mathrm{hr}$. For the remainder of the test, data was taken every $30 \mathrm{~min}$. The faster initial sampling rate was chosen to better quantify the initial creep response. The planned duration was $2000 \mathrm{hr}$ with the actual test duration being equal to $2177 \mathrm{hr}$. 
The measured total strain data was plotted as a function of time and then graphically reduced to determine the creep strains. The time (on the order of sec) required to apply the full load was recorded and the corresponding strain was defined as the initial strain to be subtracted from the total strain to obtain the creep strain. Generally, this under-predicts the creep strain as the material actually begins to creep during the load application. However, for studying the effects of process and test environments on the creep response this is an acceptable approach. In addition to the graphical interpretation of the data, a nonlinear least-squares regression algorithm was used to fit the data and determine the three parameters in the power law model. The algorithm was based on the Marquardt-Levenberg ${ }^{4}$ method to fit the total strain versus time curve. For a material that behaves according to the power law, the log of the creep strains is a linear function of the log of time.

Prior to discussing the results, it should be noted that during the 2177-hr tests two specimens had anomalies in the data. The specimen cured at $470^{\circ} \mathrm{F}$ in nitrogen and tested under vacuum had a lead-wire short out that resulted in a loss of data. The wire was repaired and the specimen was returned to the prescribed test conditions. The recorded strain was inconsistent with the previous reading and this was explained by a change in lead-wire resistance. The difference in the gage readings was determined to be acceptable in terms of comparing the data with the other data sets. The specimen cured at $520^{\circ} \mathrm{F}$ in nitrogen and tested under vacuum experienced a loss of vacuum. A vacuum seal was replaced and the specimen was returned to the prescribed test conditions. However, when exposed to the air environment the specimen had a higher creep rate and did not return to the previous strain level. The creep rate prior to losing vacuum was used to correct the data and the adjusted strains were in excellent agreement with the earlier part of the data.

The results are summarized in Table 1.3-2 for both the graphical interpretation of the data and the power law parameters. General observations from the results follow. The test specimens run under vacuum had lower creep strains than the tests run in air. Also, as shown in Fig. 1.3-1, the vacuum-tested specimens exhibited lower creep rates than the air-tested specimens. Processing the specimens in a nitrogen environment produced lower creep strains than processing in air. The combined effect of processing in nitrogen and testing under vacuum versus processing in air and testing in air was a $47 \%$ decrease in the creep strain. The test environment appeared to have a greater effect on the resin creep than the process environment. The results also show lower creep 
strains resulted from post-curing at a lower temperature (see Fig. 1.3-2). A possible explanation for this observation is a reduction in free volume produced by curing the polycyanate resin below the glass transition temperature. Finally, the effect of test temperature was very significant with the $325^{\circ} \mathrm{F}$ condition resulting in a $159 \%$ increase in creep strain over the $275^{\circ} \mathrm{F}$ condition (see Fig. $1.3-3)$.

The results for the nonlinear least-squares regression fit to the data indicated that the power law model was an excellent representation of the experimental data. In comparing the air versus vacuum test environment, the air-tested specimens had higher initial strains and time exponents but lower scale parameters. Conversely, for the air versus nitrogen process environment, the air cured specimens had higher scale parameters and lower time exponents. The effects of lowering the postcure temperature were a decrease in the scale parameter and an increase in the time exponent. An increase in the test temperature resulted in an increase in all three of the power law parameters. One further observation from the power law parameters for the air-tested specimens was that the initial strains determined from the nonlinear data fits were larger than the strains determined graphically. Typically, this is not the case and the cause and/or explanation for it is unknown.

The results from the RS-14 resin compressive creep tests demonstrated that a reduction in creep strain is possible when the resin is processed in nitrogen and tested under vacuum. This will minimize or eliminate the formation of surface oxidation and minimize any other chemical aging effects that may be accelerated by exposing this resin system to an air environment at elevated temperatures. 
Table 1.2-1. Resin compressive strength.

\begin{tabular}{|c|c|c|c|c|c|c|c|c|}
\hline \multirow{2}{*}{ Fab* } & \multicolumn{4}{|c|}{ Ambient temperature } & \multicolumn{4}{c|}{$275^{\circ} \mathrm{F}$} \\
\cline { 2 - 9 } & $\begin{array}{c}\text { Ultimate } \\
\text { strength } \\
(\mathrm{psi})\end{array}$ & $\begin{array}{c}\text { Yield } \\
\text { strength } \\
(\mathrm{psi})\end{array}$ & $\begin{array}{c}\text { Yield strain } \\
(\%)\end{array}$ & $\begin{array}{c}\text { Modulus } \\
(\mathrm{psi})\end{array}$ & $\begin{array}{c}\text { Ultimate } \\
\text { strength } \\
(\mathrm{psi})\end{array}$ & $\begin{array}{c}\text { Yield } \\
\text { strength } \\
(\mathrm{psi})\end{array}$ & $\begin{array}{c}\text { Yield strain } \\
(\%)\end{array}$ & $\begin{array}{c}\text { Modulus } \\
(\mathrm{psi})\end{array}$ \\
\hline Air/520 & 20,592 & 12,235 & 2.90 & 455,555 & 12,515 & 8915 & 2.62 & 367,044 \\
\hline N2/520T & 20,925 & 12,130 & 2.92 & 451,655 & 13,027 & 8930 & 2.73 & 356,451 \\
\hline N2/520B & 19,671 & 11,025 & 2.77 & 435,485 & 12,314 & 8325 & 2.74 & 336,364 \\
\hline N2/470 & 19.591 & 11,235 & 2.77 & 444,446 & 12,180 & 8255 & 2.49 & 354,641 \\
\hline
\end{tabular}

a Nomenclature:

Air $/ 520$ - post-cured in air at $520^{\circ} \mathrm{F}$ (autoclave)

$\mathrm{N} 2 / 520 \mathrm{~T}$ - post-cured in nitrogen at $520^{\circ} \mathrm{F}$ (top of vacuum furnace)

$\mathrm{N} 2 / 520 \mathrm{~B}$ - post-cured in nitrogen at $<520^{\circ} \mathrm{F}$ (bottom of vacuum furnace)

$\mathrm{N} 2 / 470$ - post-cured in nitrogen at $470^{\circ} \mathrm{F}$ (autoclave) 


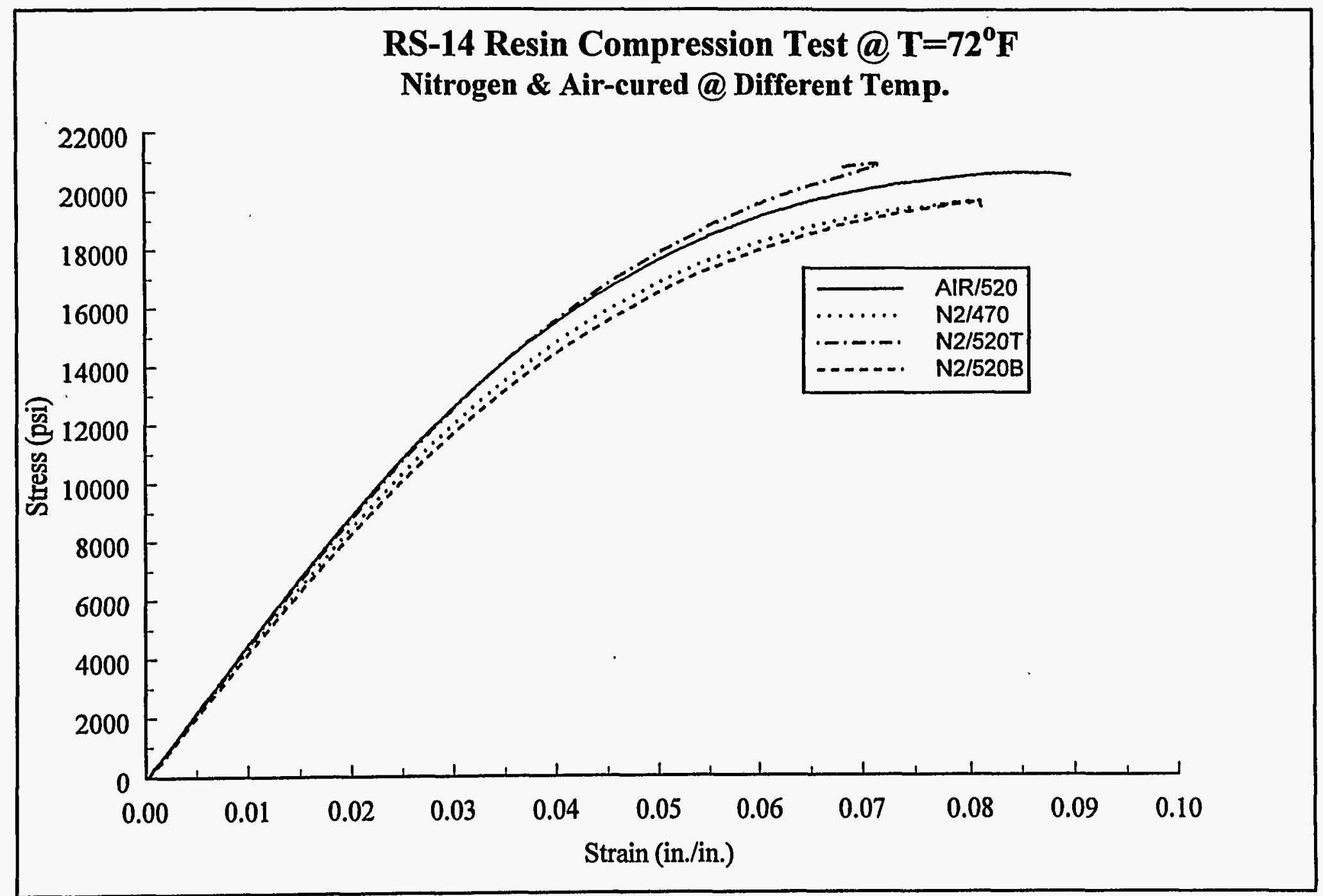

Fig. 1.2-1. Stress-strain responses for $\mathrm{RS}-14$ resin tested at ambient temperatures. 


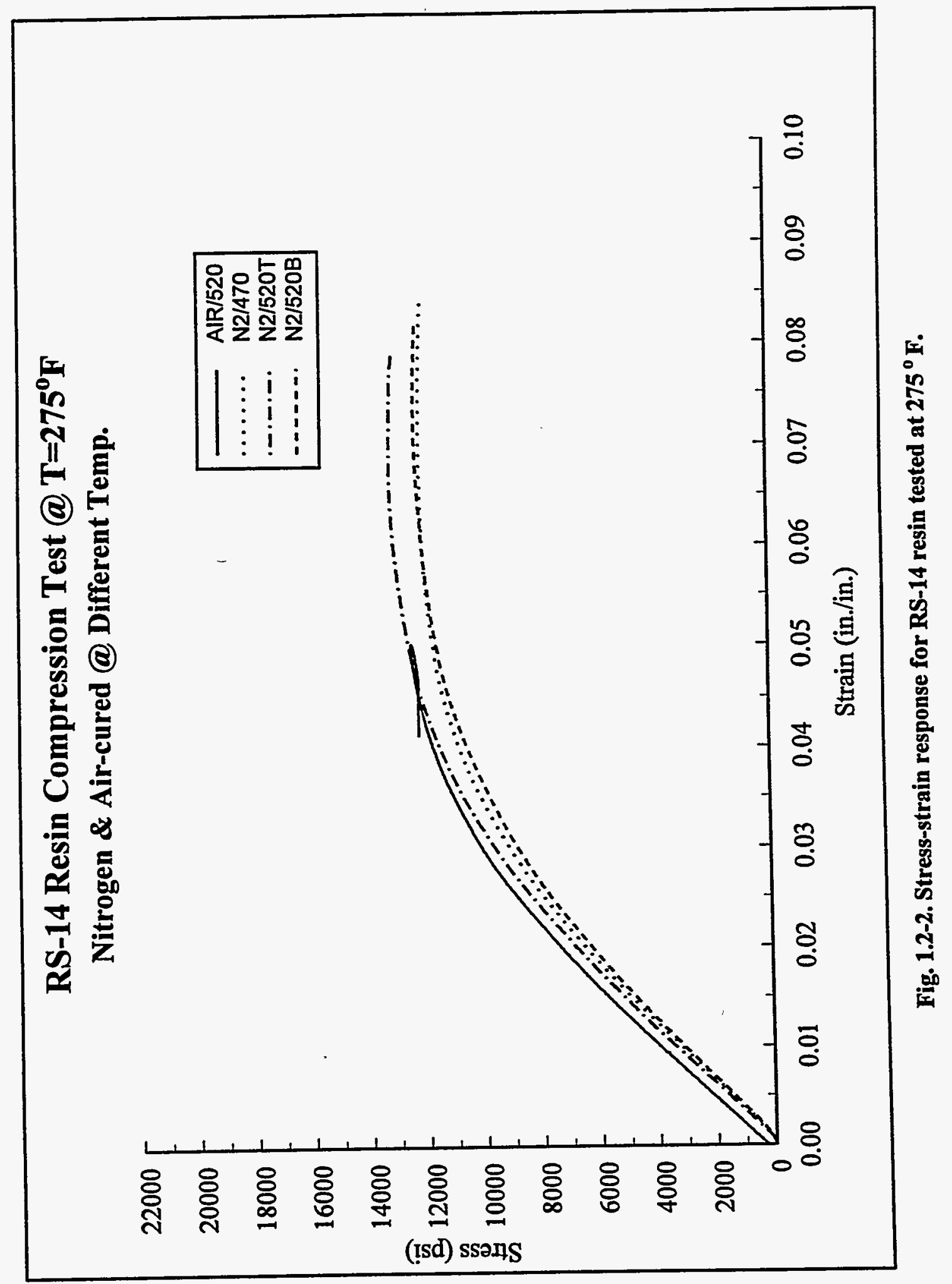


Table 1.3-1. Resin compressive creep test matrix.

\begin{tabular}{|c|c|c|c|c|}
\hline Test number & $\begin{array}{c}\text { Process } \\
\text { environment }\end{array}$ & $\begin{array}{c}\text { Post-cure } \\
\text { temperature }\left({ }^{\circ} \mathrm{F}\right)\end{array}$ & $\begin{array}{c}\text { Test } \\
\text { environment }\end{array}$ & $\begin{array}{c}\text { Test } \\
\text { temperature }\left({ }^{\circ} \mathrm{F}\right)\end{array}$ \\
\hline 5 & Air & 520 & Air & 275 \\
\hline B5 & Nitrogen & 520 & Air & 275 \\
\hline 7 & Air & 520 & Vacuum & 275 \\
\hline B9 & Nitrogen & 520 & Vacuum & 275 \\
\hline A5 & Nitrogen & 470 & Vacuum & 275 \\
\hline C5 & Nitrogen & $<520$ & Vacuum & 275 \\
\hline B7 & Nitrogen & 520 & Vacuum & 325 \\
\hline
\end{tabular}


Table 1.3-2. Results for RS-14 resin compressive creep tests

\begin{tabular}{|c|c|c|c|c|c|c|c|c|c|c|}
\hline \multirow{2}{*}{$\begin{array}{c}\text { Spec. } \\
\text { no. }\end{array}$} & \multirow{2}{*}{ Fab } & \multirow{2}{*}{$\begin{array}{c}\text { Test } \\
\text { temp. } \\
\left({ }^{\circ} \mathrm{F}\right)\end{array}$} & \multirow{2}{*}{$\begin{array}{l}\text { Test } \\
\text { environment }\end{array}$} & \multicolumn{3}{|c|}{ Graphical results } & \multicolumn{4}{|c|}{ Power law results (nonlinear data fit) ${ }^{\mathrm{a}}$} \\
\hline & & & & $\begin{array}{c}\text { Initial } \\
\text { strain } \\
(\%)\end{array}$ & $\begin{array}{c}\text { Final } \\
\text { strain } \\
(\%)\end{array}$ & $\begin{array}{c}\text { Creep } \\
\text { strain } \\
(\%)\end{array}$ & $\begin{array}{c}\text { Initial } \\
\text { strain (\%) }\end{array}$ & $\begin{array}{c}\text { Scale } \\
\text { parameter }\end{array}$ & $\begin{array}{c}\text { Time } \\
\text { exponent }\end{array}$ & $\mathbf{R}$ \\
\hline 5 & Air/520 & 275 & Air & 0.8548 & 1.8321 & 0.9773 & 0.8911 & 0.007270 & 0.3049 & 0.9995 \\
\hline 7 & Air/520 & 275 & Vacuum & 0.6861 & 1.3650 & 0.6789 & 0.4846 & 0.122578 & 0.1249 & 0.9990 \\
\hline B5 & $\mathrm{N} 2 / 520 \mathrm{~T}$ & 275 & Air & 0.8378 & 1.6133 & 0.7755 & 0.8770 & 0.004806 & 0.3154 & 0.9995 \\
\hline B9 & $\mathrm{N} 2 / 520 \mathrm{~T}$ & 275 & Vacuum & 0.7013 & 1.2168 & 0.5155 & 0.5637 & 0.081018 & 0.1327 & 0.9987 \\
\hline $\mathrm{C} 5$ & $\mathrm{~N} 2 / 520 \mathrm{~B}$ & 275 & Vacuum & 0.7229 & 1.2211 & 0.4982 & 0.5981 & 0.074747 & 0.1341 & 0.9994 \\
\hline A5 & $\mathrm{N} 2 / 470$ & 275 & Vacuum & 0.5992 & 1.0478 & 0.4486 & 0.5052 & 0.057570 & 0.1427 & 0.9987 \\
\hline B7 & $\mathrm{N} 2 / 520 \mathrm{~T}$ & 325 & Vacuum & 0.8680 & 2.2038 & 1.3358 & 0.6005 & 0.131797 & 0.1568 & 0.9991 \\
\hline
\end{tabular}

" Power law equation: $\epsilon(t)=\epsilon_{0}+m t^{n}$

where: $\epsilon(t)=$ total strain

$\epsilon_{0}=$ initial strain

$\mathrm{m}=$ scale parameter

$\mathrm{n}=$ time exponent

$\mathrm{R}=$ correlation coefficient 


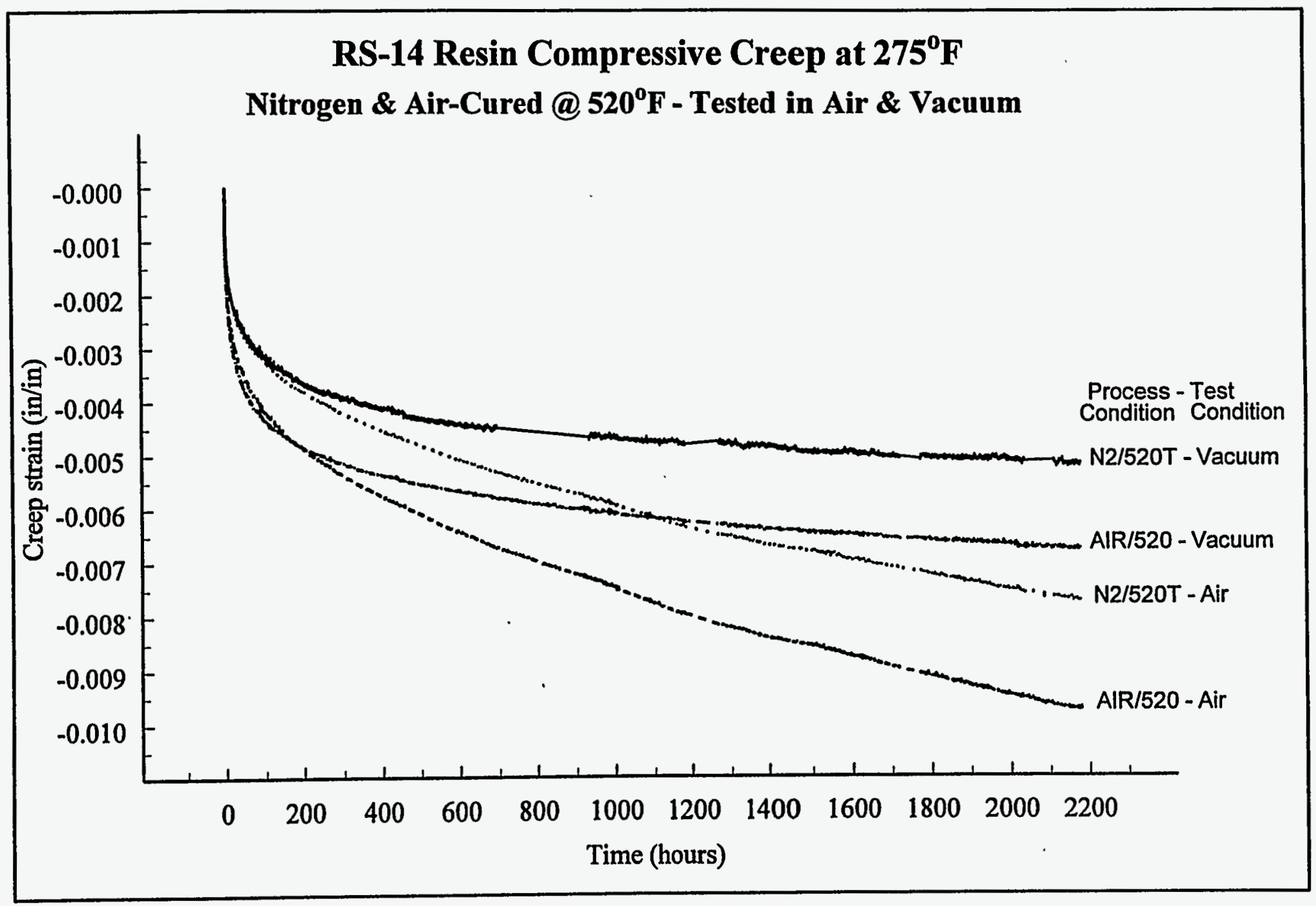

Fig. 1.3-1. Effect of process and test environments on RS-14 resin compressive creep. 


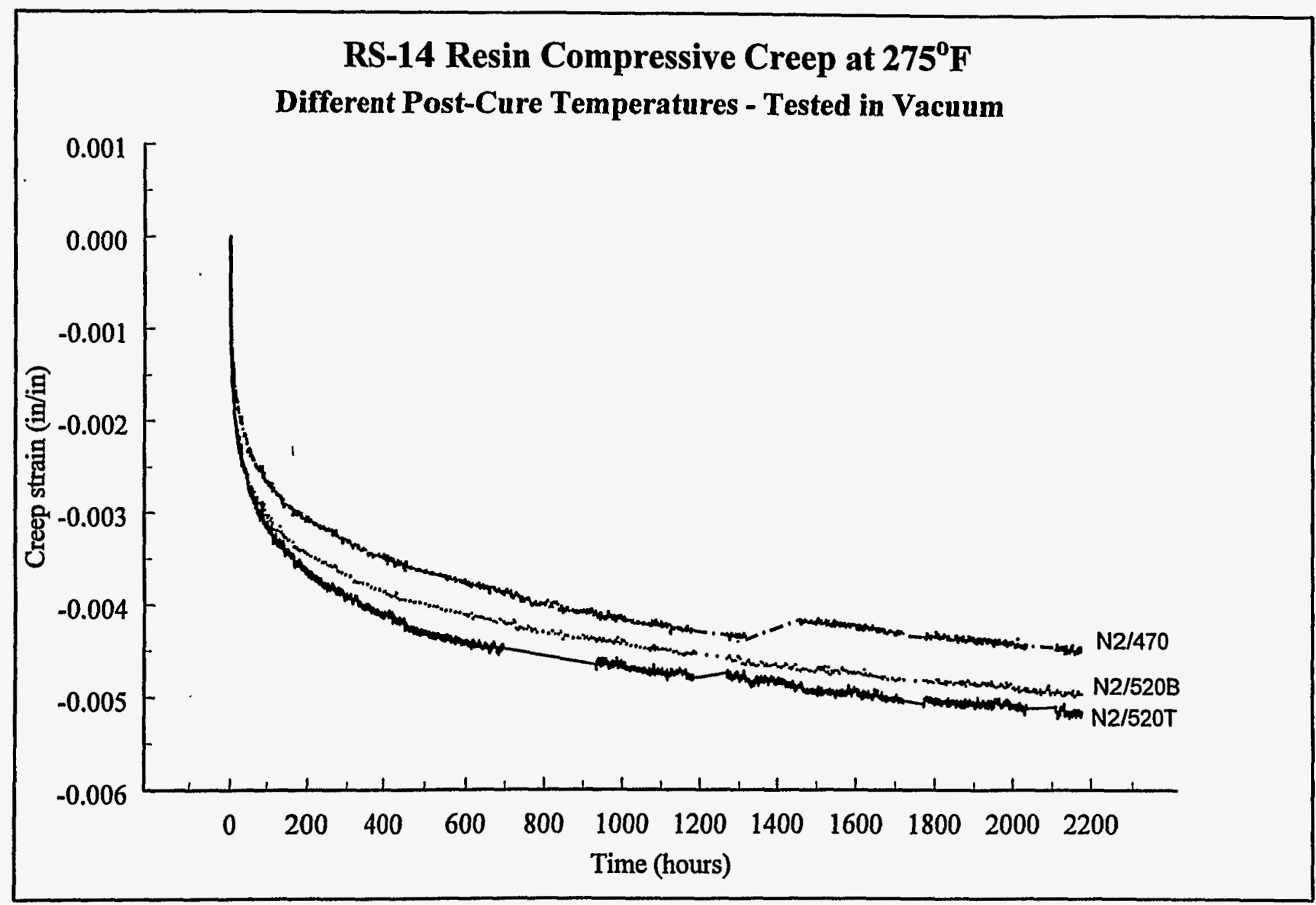

Fig. 1.3-2. Effect of post-cure temperature on $\mathrm{RS}-14$ resin compressive creep. 


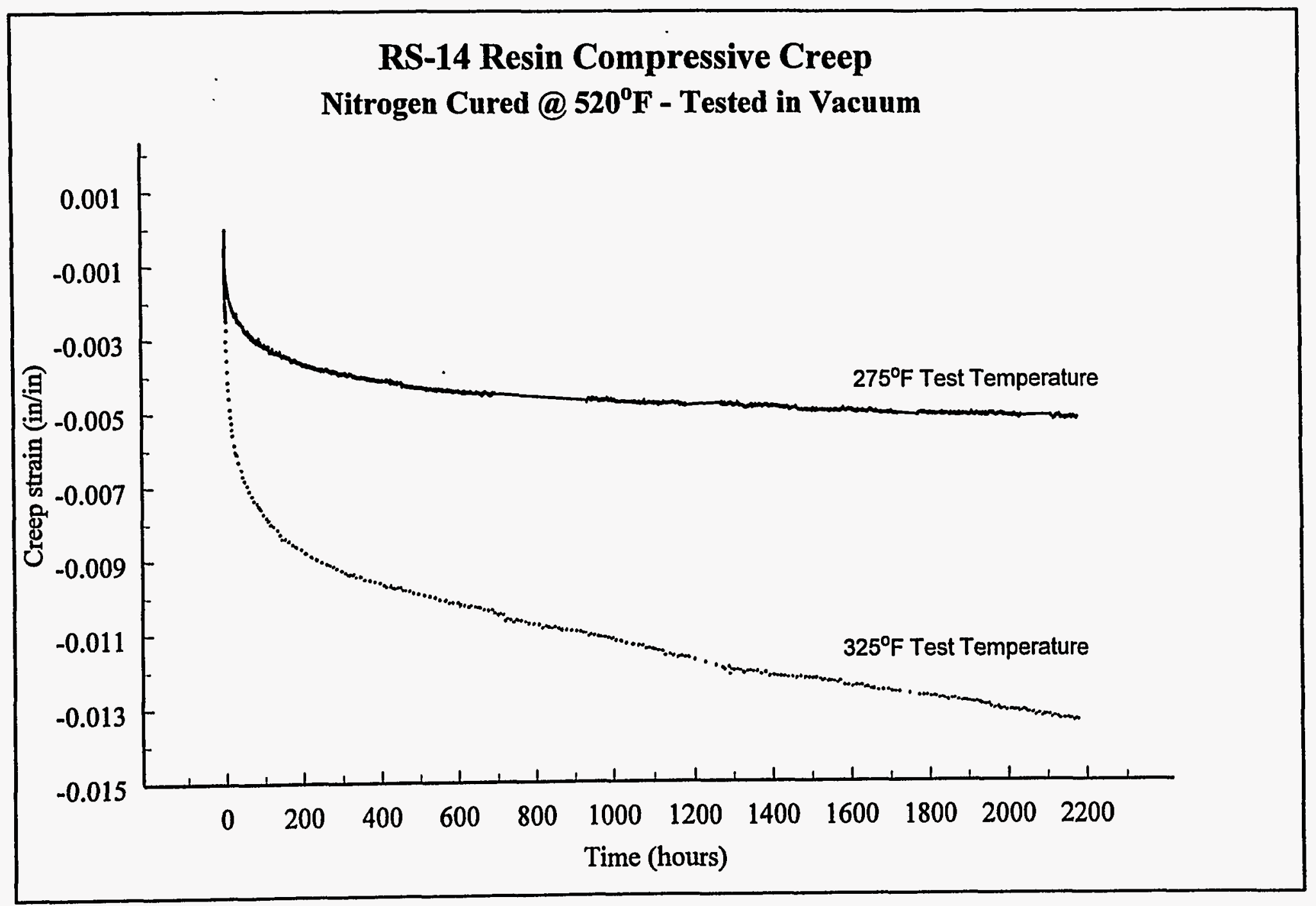

$\varpi$

Fig. 1.3-3. Effect of test temperature on RS-14 resin compressive creep. 


\section{T1000G/RS-14 COMPOSITE TRANSVERSE COMPRESSIVE RESPONSE}

Following the conclusion of the resin creep tests, the effects of the process and test environment on the composite creep response were quantified by conducting another set of tests. This series of tests also investigated the effects of initial stress level and test temperature on the creep behavior. All of the specimens were post-cured in a nitrogen environment and all tests were conducted in a vacuum environment. In addition to the creep testing efforts, transverse compressive strength tests were conducted to calculate a B-Basis allowable and to determine the transverse compressive stress-strain response of the composite material system.

\subsection{Composite Specimen Fabrication}

The specimens were machined from a 1 in. radially thick composite cylinder. The cylinder was wet-filament wound on a 14 in. diameter internally heated steel mandrel using T1000G fiber and RS-14 resin. The $1 \mathrm{in}$.-thick cylinder was wound in nominal 1/4in.-thick stages per day over a 4-day period. Each stage took approximately $4 \mathrm{hr}$ to complete before the mandrel could be moved from the winding machine to the oven. To minimize the potential for carbamate formation from exposure of the resin to ambient humidity in the vicinity of the winding machine (Shimp and Ising ${ }^{5}$ ), winding was accomplished on days when the relative humidity in the laboratory was $40 \%$ or less. The pot temperature was maintained between $175^{\circ}-180^{\circ} \mathrm{F}$ and the fiber tension was $12 \mathrm{lb}$. Every layer was compacted and wiped during winding. An additional two compaction passes with wiping were also applied after every five-layer winding increment.

The internal heaters of the mandrel were used to maintain the mandrel OD surface temperature between $170^{\circ}-180^{\circ} \mathrm{F}$. The composite surface temperature was also maintained between $170^{\circ}-180^{\circ} \mathrm{F}$. As the winding progressed, the thickening composite acted as an insulation layer and an external strip heater was required to maintain the composite surface temperature.

The last carbon fiber layers wound on the first, second, and third stages were wiped dry prior to moving the mandrel to the oven for pre-cure. The purpose was to remove excess resin so that there would not be an excessively thick resin layer between the composite stages after cure. Excess resin that bled out during the pre-cure was sanded to roughen the surface and degreased with acetone 
prior to winding the next stage. The last layer of the fourth and final stage was left slightly resin rich to protect the carbon fiber at the OD of the composite.

After completion of each 1/4 in.-thick stage, the mandrel was moved from the winding machine to a rotisserie cart and sealed within a metal canopy. The canopy was purged with nitrogen gas and the mandrel temperature was raised to $380^{\circ} \mathrm{F}$ at approximately $0.5-1^{\circ} \mathrm{F} / \mathrm{min}$ and held at that temperature for $3 \mathrm{hr}$ to complete the pre-cure.

After the pre-cure of the fourth and final stage, the mandrel was allowed to return to ambient temperature and the seal of the metal can was inspected to ensure that there would be no air leakage into the canopy during the elevated temperature post-cure. Following inspection, the canopy was purged with nitrogen gas and the mandrel temperature was raised to $500^{\circ} \mathrm{F}$ at approximately $0.5-$ $1^{\circ} \mathrm{F} / \mathrm{min}$ and held at that temperature for $4 \mathrm{hr}$ to complete the post-cure of the composite.

Oxygen levels were measured with an oxygen analyzer during the $500^{\circ} \mathrm{F}$ portion of the cure cycle and ranged between 1 to $2 \%$. The outer resin layer of the composite cylinder was examined visually and had a brown tint instead of the dark black color typical of cylinders that have been postcured in air. This information suggests that the process used to fabricate the T1000G/RS-14 compressive creep test cylinders was successful at preventing resin surface oxidation during the cure cycle.

A 1-3/4 in. wide ring was cut from this cylinder for machining both the creep and static strength specimens. The machined circumferential width for the creep specimens was 0.5 in., whereas, the strength specimens were $1.0 \mathrm{in}$. wide (see Fig. 2.1-1). This was to minimize the effects of machining and local surface damage on the static compressive strength measurement. Similar to the resin creep specimens, this geometry produced a radius of gyration within the specified limits of the ASTM D695M-85 standard test method.

\subsection{Composite Transverse Compressive Strength}

The composite transverse compressive strength was determined by loading the specimens transverse to the fibers along the direction parallel to the axis of the cylinder. The specimens were strain gaged to determine the ultimate strain and to calculate an initial modulus. A strain range of 0.1 to $0.6 \%$ was used for the modulus calculations. A total of 20 specimens were tested at both 
ambient and $275^{\circ} \mathrm{F}$ test temperatures. This provided 10 tests at each temperature, which was a sufficient number of data points to reliably calculate a B-Basis allowable. The results are shown in Table 2.2-1 along with the data from previous tests conducted on specimens that had been cured in an air environment. The results indicate that the process conditions did not significantly affect the B-Basis allowable. The average strength for the nitrogen-cured specimens actually decreased, but with a corresponding reduction in the scatter the B-Basis was slightly greater than the air-cured results. Similar to the neat resin strength results, the effect of test temperature was significant with a $22 \%$ reduction in strength at $275^{\circ} \mathrm{F}$ compared to the ambient temperature strength. However, there was a less than $10 \%$ reduction in modulus and ultimate strain. A typical stress-strain curve for both test temperatures is provided in Fig. 2.2-1.

\subsection{Composite Transverse Compressive Creep}

The test matrix for the composite transverse compressive creep tests is shown in Table 2.3-1. The specimens were loaded transverse to the fiber direction using the same creep stands and fixtures as described for the resin creep tests. Also, the same type of instrumentation and data acquisition system was utilized. The data was collected and reduced for a total test duration of $2000 \mathrm{hr}$. The results for the 10,000 -psi stress level at $275^{\circ} \mathrm{F}$ were compared to the results from a baseline test conducted on an air-cured specimen tested in an air environment. According to the stress-strain curves plotted in Fig. 2.2-1 for the nitrogen-cured specimens, the 6000-psi stress level was well within the initial linear portion of the curve. However, the 10,000-psi applied stress was very close to the point where the stress-strain response begins to deviate from the initial linear response.

The measured total strains are plotted in Fig. 2.3-1 and the data was reduced as described in Sect. 1.3. The graphical interpretation of the results along with the power law parameters are summarized in Table 2.3-2. The results for the graphical interpretation of the data show a significant increase in creep strain between the $200^{\circ} \mathrm{F}$ test temperature and the $275^{\circ} \mathrm{F}$ temperature (Fig. 2.3-2) and between the 6000-psi applied stress and the 10,000-psi stress (Fig. 2.3-3). This is also shown graphically in Fig. 2.3-4, where the creep strains are plotted for the various test conditions. The specimen that was nitrogen-cured and vacuum tested at $275^{\circ} \mathrm{F}$ and subjected to the 10,000 -psi stress, i.e., specimen 29 , had creep strains that were $19 \%$ less than the equivalent air-cured specimen, C6. 
The effects of process and test environment on the creep behavior are not as great for the composite system as they were for the neat resin. This is primarily because of the low resin content in the composite material system.

The power law model provided an excellent representation of the experimental data as shown in Fig. 2.3-5. The creep strains plotted in this figure were calculated by subtracting from the total strain the initial strain determined from the nonlinear least-squares regression fit of the data. This figure also demonstrates the reduced creep of the nitrogen-cured/vacuum-tested specimen compared to the air-cured/air-tested specimen. In using the initial strain from the power law fit to compute creep strains, the differences between the two data sets are not as great as the graphical results previously discussed. It should be pointed out, that not all of the reduced creep is due to the processing and testing environments because the $\mathrm{C} 6$ specimen had a slightly higher applied stress, 10,658 psi, versus 10,020 psi for specimen 29 . In terms of the power law parameters, the aircured/air-tested specimen had a larger initial strain, a smaller scale parameter, and a larger time exponent than the nitrogen-cured/vacuum-tested specimen. This is consistent with the trends observed in the neat resin compressive creep tests. The effects of an increase in stress on the power law parameters were larger initial strains, larger scale parameters, and smaller time exponents. The effects of an increase in temperature were shown to be larger initial strains and larger time exponents.

The power law model was used to make a 10-year prediction for the transverse compressive strains. The total strain predicted after ten years is in excess of $1.0 \%$ only for the highest stress level of $10,000 \mathrm{psi}$ and the largest test temperature of $275^{\circ} \mathrm{F}$. The static stress-strain curves indicate that a transverse compressive strain of $1.0 \%$ corresponds to $70 \%$ of the ultimate strain when the composite system is exposed to $275^{\circ} \mathrm{F}$. Consequently, under these conditions there is still a small safety factor on the transverse compressive strain. The 10-year predicted creep strains are compared in Fig. 2.3-6 for the air-cured/air-tested specimen (C6) and the nitrogen-cured/vacuum-tested specimen (29). For the 10-year exposure, the reduction in creep strains for the nitrogencured/vacuum-tested specimen compared to the air-cured/air-tested sample is $18.8 \%$. 


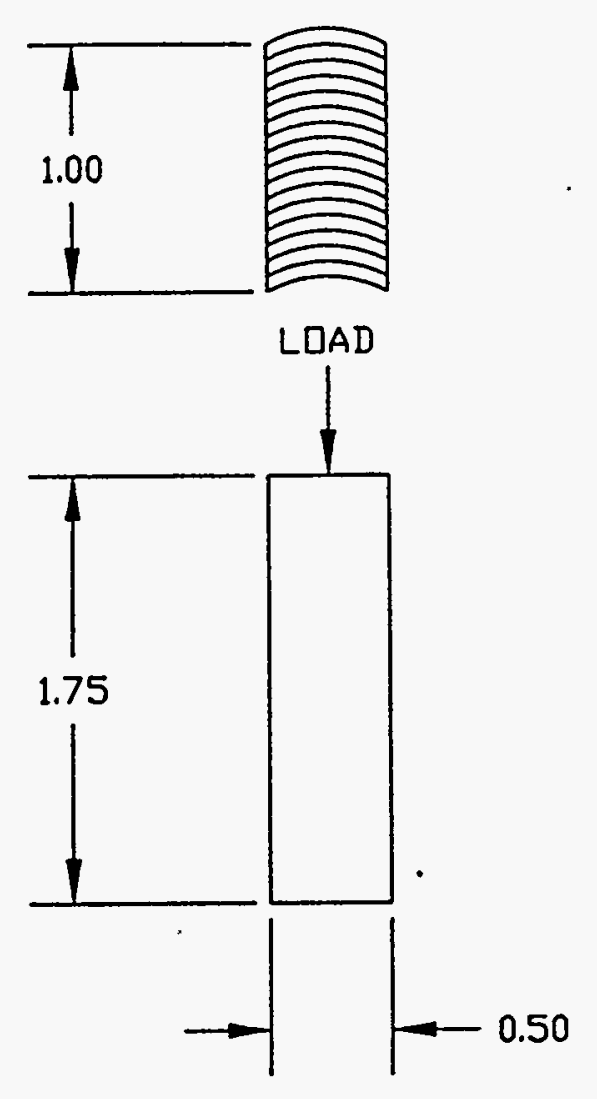

a.) Creep specimen

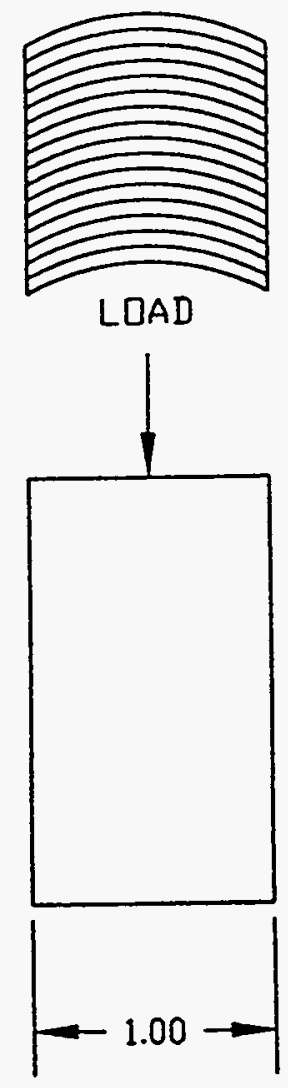

b.) Strength specimen

Fig. 2.1-1. Composite transverse compression test specimen geometries. 
Table 2.2-1. Results from composite transverse compressive strength tests.

\begin{tabular}{|c|c|c|c|c|c|c|}
\hline $\begin{array}{c}\text { Process } \\
\text { condition }\end{array}$ & $\begin{array}{c}\text { Test temperature } \\
\left({ }^{\circ} \mathrm{F}\right)\end{array}$ & $\begin{array}{c}\text { Average } \\
\text { strength }(\mathrm{psi})\end{array}$ & $\begin{array}{c}\text { C.V. } \\
(\%)\end{array}$ & B-basis (psi) & $\begin{array}{c}\text { Ultimate strain } \\
(\%)\end{array}$ & Modulus (psi) \\
\hline Nitrogen & 72 & 22,769 & 5.28 & 19,390 & 1.57 & $1.57 \times 10^{6}$ \\
\hline Nitrogen & 275 & 17,813 & 2.47 & 16,480 & 1.43 & $1.46 \times 10^{6}$ \\
\hline Air & 275 & 20,119 & 7.66 & 16,292 & 1.58 & $1.50 \times 10^{6}$ \\
\hline
\end{tabular}




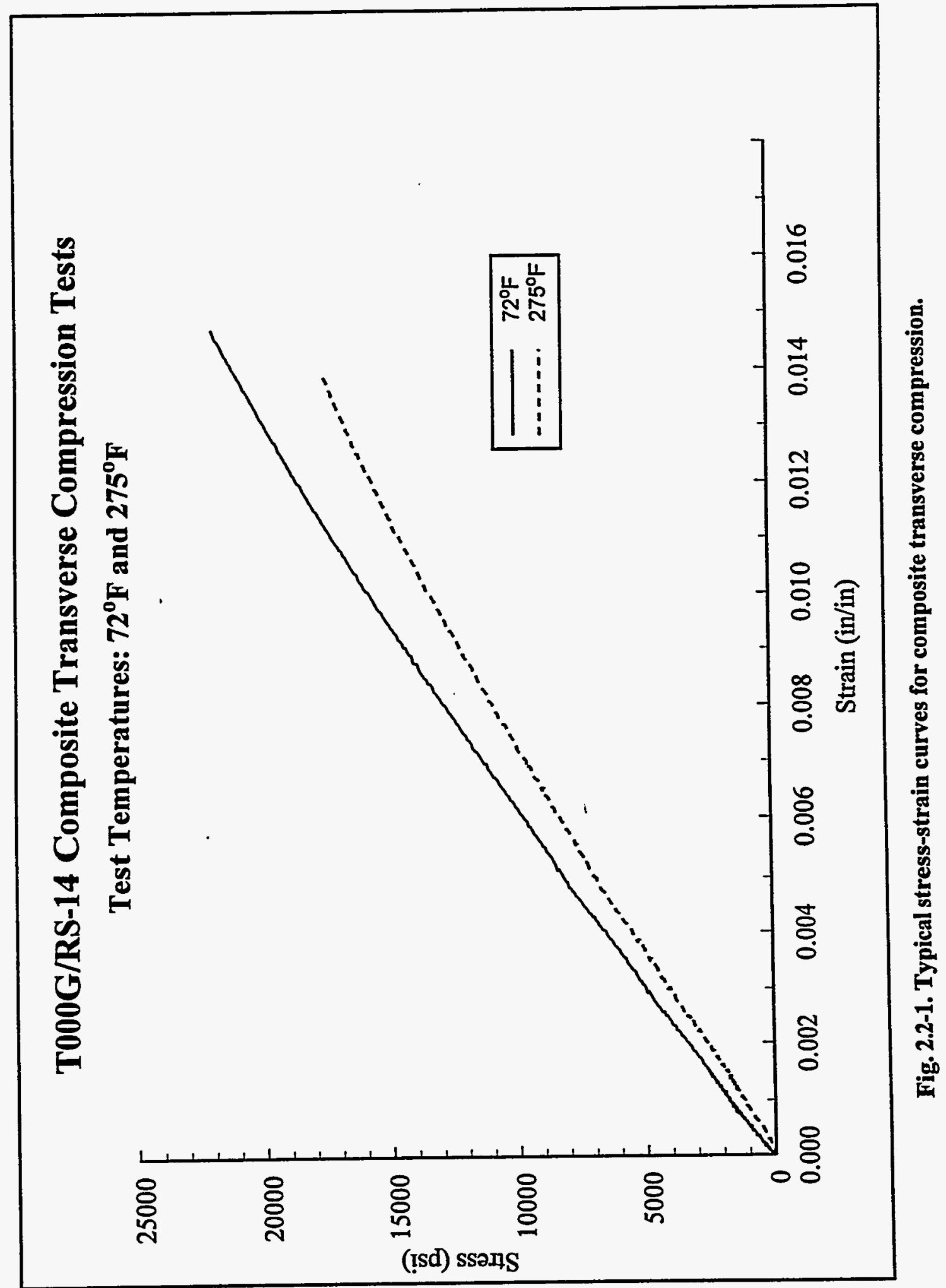


Table 2.3-1. Test matrix for composite transverse compressive creep tests.

\begin{tabular}{|c|c|c|c|}
\hline Test number & Stress level $(\mathrm{psi})$ & Test temperature $\left({ }^{\circ} \mathrm{F}\right)$ & Test environment \\
\hline 1 & 10,000 & 72 & Vacuum \\
\hline 2 & 6,000 & 140 & Vacuum \\
\hline 3 & 10,000 & 140 & Vacuum \\
\hline 4 & 6,000 & 200 & Vacuum \\
\hline 5 & 10,000 & 200 & Vacuum \\
\hline 6 & 6,000 & 275 & Vacuum \\
\hline 7 & 10,000 & 275 & Vacuum \\
\hline
\end{tabular}


Table 2.3-2. Results for the T1000G/RS-14 composite transverse compressive creep tests

\begin{tabular}{|c|c|c|c|c|c|c|c|c|c|c|c|}
\hline \multirow{2}{*}{$\begin{array}{l}\text { Spec. } \\
\text { no." }\end{array}$} & \multirow{2}{*}{$\begin{array}{c}\text { Temp. } \\
\left({ }^{\circ} \mathrm{F}\right)\end{array}$} & \multirow{2}{*}{$\begin{array}{c}\text { Stress } \\
\text { (psi) }\end{array}$} & \multicolumn{3}{|c|}{ Graphical results } & \multicolumn{4}{|c|}{ Power law parameter (nonlinear data fit) ${ }^{b}$} & \multicolumn{2}{|c|}{ 10-year prediction } \\
\hline & & & $\begin{array}{c}\text { Initial } \\
\text { strain } \\
(\%)\end{array}$ & $\begin{array}{c}\text { Final } \\
\text { strain } \\
(\%)\end{array}$ & $\begin{array}{c}\text { Creep } \\
\text { strain } \\
(\%)\end{array}$ & $\begin{array}{c}\text { Initial } \\
\text { strain } \\
(\%)\end{array}$ & $\begin{array}{c}\text { Scale } \\
\text { parameter } \\
(\%)\end{array}$ & $\begin{array}{c}\text { Time } \\
\text { exponent }\end{array}$ & $\mathbf{R}$ & $\begin{array}{c}\text { Final } \\
\text { strain (\%) }\end{array}$ & $\begin{array}{c}\text { Creep strain } \\
(\%)\end{array}$ \\
\hline 21 & 140 & 5999 & 0.4334 & 0.4727 & 0.0393 & 0.4094 & 0.0203 & 0.0719 & 0.9951 & 0.4924 & 0.0830 \\
\hline 23 & 200 & 6002 & 0.4465 & 0.5008 & 0.0543 & 0.4219 & 0.0191 & 0.0903 & 0.9974 & 0.5336 & 0.1117 \\
\hline 27 & 275 & 5998 & 0.4753 & 0.5832 & 0.1079 & 0.4470 & 0.0184 & 0.1272 & 0.9986 & 0.6693 & 0.2223 \\
\hline 17 & 72 & 10,164 & 0.5498 & 0.5917 & 0.0419 & 0.5229 & 0.0215 & 0.0742 & 0.9953 & 0.6150 & 0.0921 \\
\hline 19 & 140 & 9996 & 0.5923 & 0.6681 & 0.0758 & 0.5419 & 0.0538 & 0.0538 & 0.9980 & 0.6964 & 0.1544 \\
\hline 30 & 200 & 10,012 & 0.6711 & 0.7597 & 0.0886 & 0.6097 & 0.0535 & 0.0652 & 0.9997 & 0.8016 & 0.1919 \\
\hline 29 & 275 & 10,020 & 0.6918 & 0.9504 & 0.2586 & 0.5809 & 0.0849 & 0.0939 & 0.9994 & 1.1143 & 0.5334 \\
\hline C6 & 275 & 10,658 & 0.7497 & 1.0701 & 0.3204 & 0.6662 & 0.0550 & 0.1268 & 0.9995 & 1.3236 & 0.6574 \\
\hline
\end{tabular}

"Specimens 17, 19, 30, 29, 21, 23, 27 were processed in nitrogen and tested under vacuum, and specimen C6 was processed in air and tested in air.

${ }^{b}$ Power law equation: $\epsilon(t)=\epsilon_{0}+m t^{n}$, where: $\epsilon(t)=$ total strain

$\epsilon_{\mathrm{o}}=$ initial strain

$\mathrm{m}=$ scale parameter

$\mathrm{n}=$ time exponent

$\mathrm{R}=$ correlation coefficient 


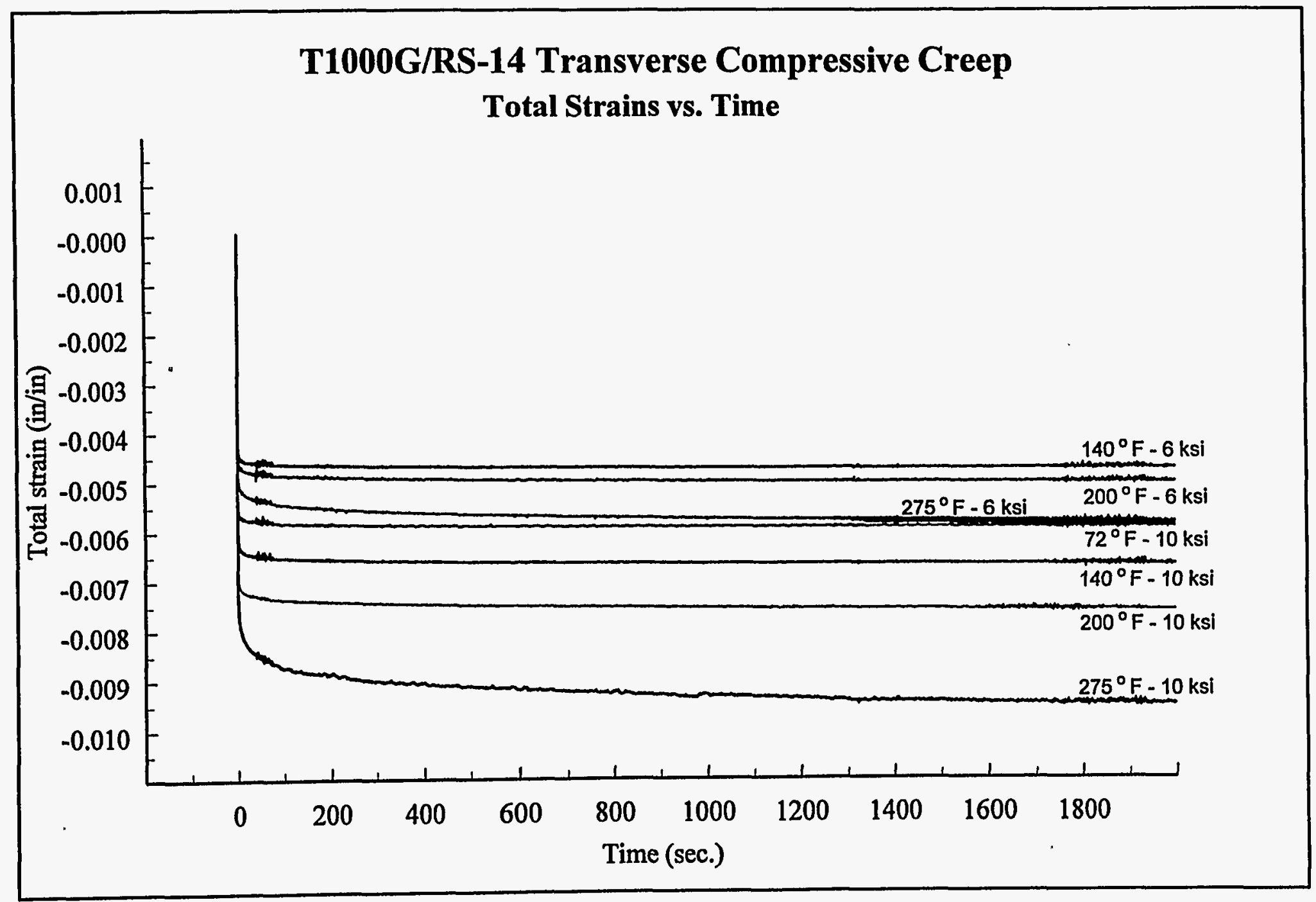

Fig. 2.3-1. Total strains for composite transverse compressive creep tests. 


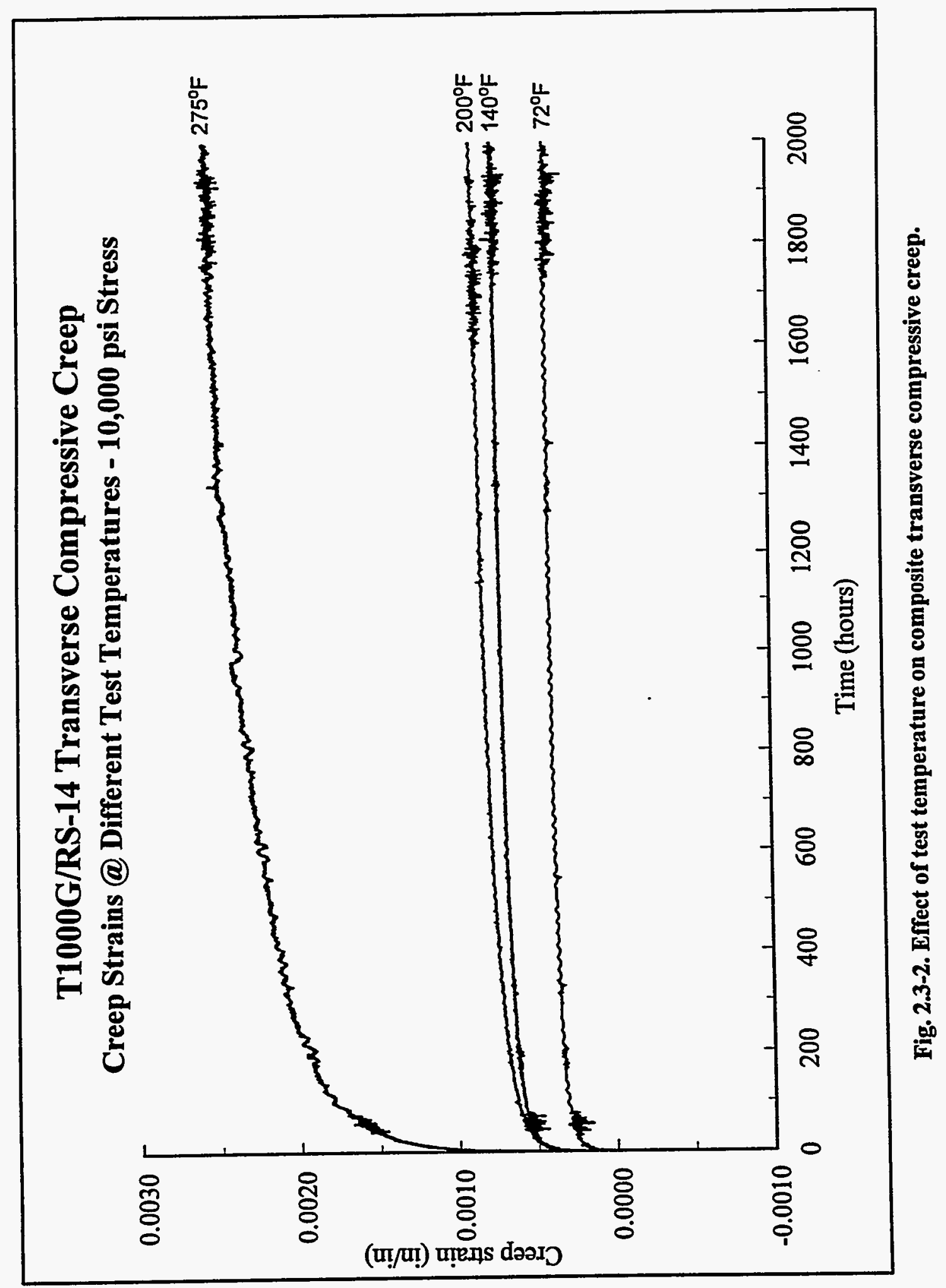




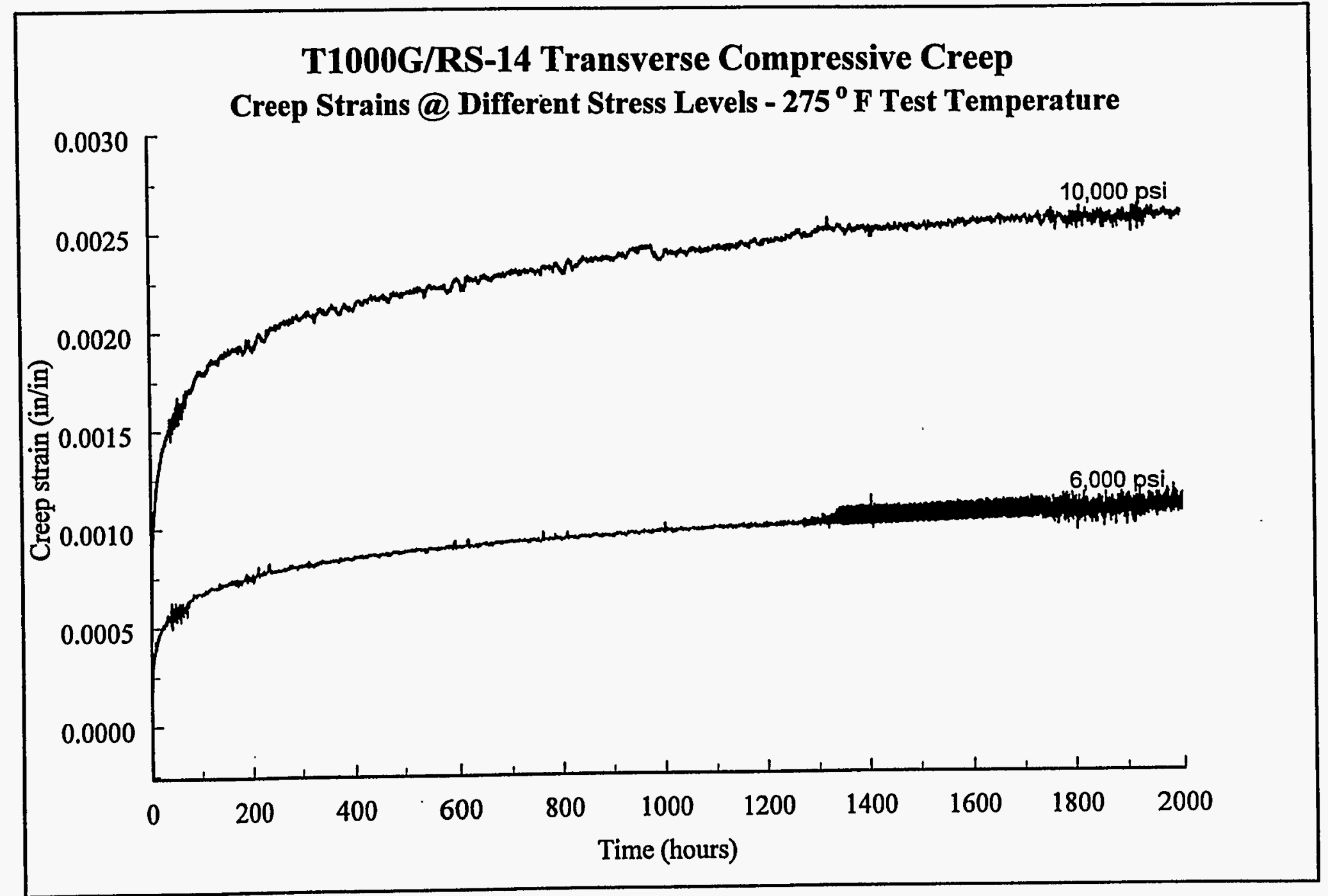

Fig. 2.3-3. Effect of applied stress level on composite transverse compressive creep. 


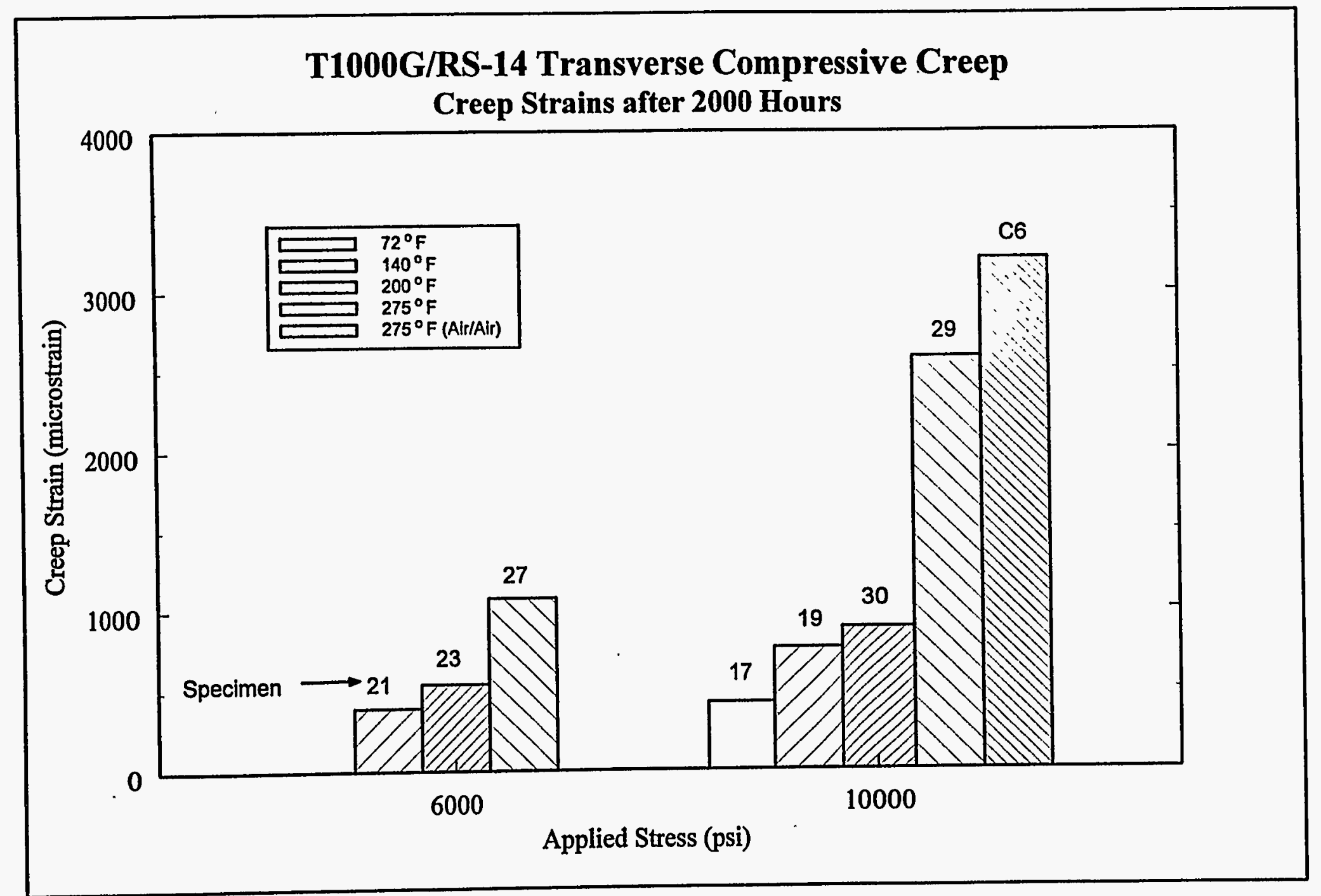

Fig. 2.3-4. Magnitude of creep strains for composite transverse compressive creep. 


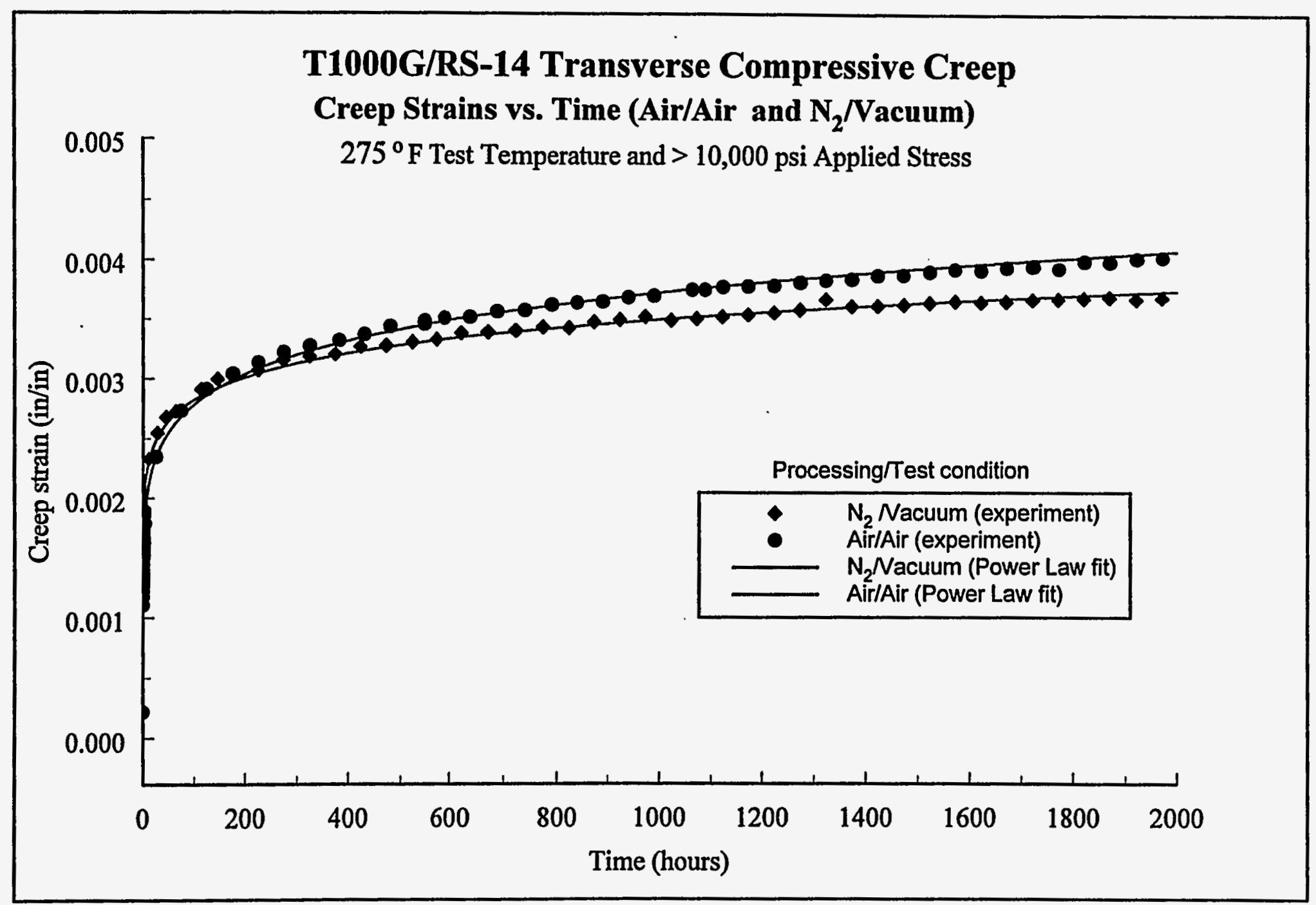

Fig. 2.3-5. Nonlinear least-squares regression fit for power law parameters. 


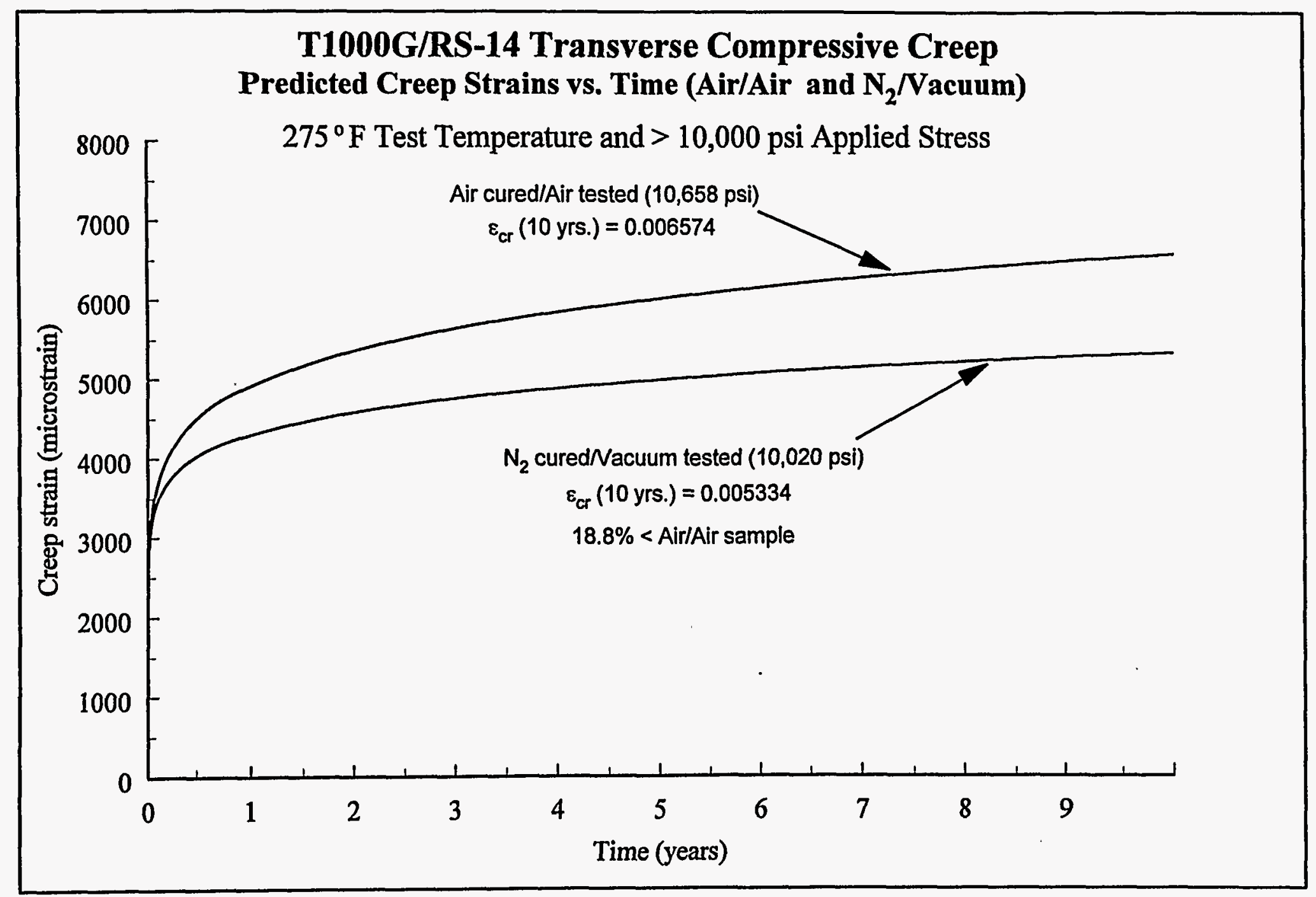

Fig. 2.3-6. Ten-year prediction based on power law model. 


\section{DISCUSSION OF RESULTS}

Composite material characterization tests were completed to characterize the compressive behavior of the RS-14 resin and the T1000G/RS-14 composite system. Mechanical property tests were conducted for both static strength and creep, and the significant findings are as follows.

1. The process environment and post-cure temperature had a minimal effect on the RS-14 resin compressive strength and modulus.

2. There was a $38 \%$ reduction in strength and a $21 \%$ reduction in modulus for testing the RS- 14 resin in compression at $275^{\circ} \mathrm{F}$ versus ambient temperature.

3. Processing the $\mathrm{T} 1000 \mathrm{G} / \mathrm{RS}-14$ composite in a nitrogen environment did not increase the B-Basis allowable for transverse compressive strength.

4. There was a $22 \%$ reduction in the composite transverse compressive strength at $275^{\circ} \mathrm{F}$ compared to the ambient test temperature.

5. The combined effect of processing in nitrogen and testing in vacuum versus processing in air and testing in air on the RS-14 resin compressive creep was a 47\% decrease in creep strain after $2177 \mathrm{hr}$, where the testing environment had the largest effect on the measured response.

6. A lower post-cure temperature resulted in smaller resin compressive creep strains.

7. There was significant increase in composite transverse compressive creep strains between the 200 and $275^{\circ} \mathrm{F}$ test temperatures, and between the 6,000 and 10,000 psi applied stress levels. 
8. At the end of the 2000-hr tests, the nitrogen-processed and vacuum-tested conditions reduced the composite transverse compressive creep strain by $19 \%$ compared to processing in air and testing in air. The 10 -year prediction for the reduction in creep strain was $18.8 \%$. 


\section{RECOMMENDATIONS}

The power law exponent for creep of epoxy resin systems is typically around $0.2-0.3$. The results from the resin compressive creep tests indicate that the RS-14 polycyanate resin will have lower creep strains than an epoxy system provided that precautions are taken during processing and testing to minimize the effects of moisture exposures.

The results from the composite transverse compressive creep tests under vacuum at 10,000 psi initial stress and $275^{\circ} \mathrm{F}$ temperature conditions led to a $1.1 \%$ total strain predicted after 10 years. The static ultimate strain for the T1000G/RS-14 material was measured to be $1.4 \%$ under elevated temperature test conditions. The results also showed that the nitrogen process and vacuum test environments significantly reduced the creep strains. However, under the conditions of high transverse compressive stress and high temperature the safety margin may not be sufficient for dimensional stability.

The results for the 10-year predictions were used, along with an approximate linear extrapolation, to obtain estimates for strains that correspond to relaxed conditions of an applied stress of $3000 \mathrm{psi}$ and a temperature of $140^{\circ} \mathrm{F}$. The results are a total strain of $0.23 \%$ with only $0.03 \%$ creep strain, where $85 \%$ of the total strain is comprised of the initial elastic strain. This is significantly less than the $1.1 \%$ total strain predicted for the $10,000 \mathrm{psi}$ and $275^{\circ} \mathrm{F}$ conditions. This is an encouraging result, however it must be verified by conducting future tests at $3000 \mathrm{psi}$ and $140^{\circ} \mathrm{F}$.

The dimensional stability of the T1000G/RS-14 system, in terms of its transverse compressive creep response, may be acceptable at higher temperatures provided that the compressive stresses are kept to a minimum. This may be accomplished by using a laminate architecture that increases the transverse stiffness. 


\section{ACKNOWLEDGMENTS}

The author would like to thank Darrel Howard and Alvin Ellis at the K-25 Technical Division, Mechanical Property Testing and Analysis for their efforts in conducting all of the tests. Also, thanks are given to the composite manufacturing personnel, Barbara Frame, Ron Meyers, Ken Yarborough, Dan Skidmore, and Tommy Thompson, for the outstanding job they performed in the wet-filament winding of the composite test cylinder, and to Ronny Lomax for fabricating the resin specimens. 


\section{REFERENCES}

1. Frame, B. J. and Starbuck, J. M., "Wet-Filament Winding Fabrication of High Strength Carbon Fiber/Polycyanate Resin Composites," presented at the $41^{\text {st }}$ International SAMPE Symposium, March 25-28, 1996, Anaheim, California, Society for the Advancement of Material and Process Engineering.

2. Frame, B. J., "Process Study of Polycyanate Resin for Wet-Filament Wound High-Strength Composites," ORNL/TM-13387, Oak Ridge National Laboratory, Oak Ridge, Tennessee, 1997.

3. Starbuck, J. M., "Testing and Performance Evaluation of T1000G/RS-14 Graphite/Polycyanate Composite Materials," ORNL-6915, Oak Ridge National Laboratory, Oak Ridge, Tennessee, January, 1997.

4. Marquardt, D. W., "An Algorithm for Least Squares Estimation of Nonlinear Parameters," Journal of the Society for Industrial and Applied Mathematics, 2, 1963, pp. 431-441.

5. Shimp, D. A. and Ising, S. J., "Moisture Effects and Their Control in the Curing of Polycyanate Resins," presented at the ASC National Meeting, PMSE Division, San Francisco, April, 1992. 